\title{
A Comparative Investment Analysis of Batch Versus Continuous Pharmaceutical Manufacturing Technologies
}

\author{
Clifford V. Rossi ${ }^{1}$ (])
}

Accepted: 1 December 2021 / Published online: 31 January 2022

(c) The Author(s), under exclusive licence to Springer Science+Business Media, LLC, part of Springer Nature 2022

\begin{abstract}
Purpose This study examines the risks and economics associated with investing in continuous (CM) versus conventional batch manufacturing for production of oral solid dosage pharmaceutical (OSD) products in the USA and abroad.

Methods A stochastic net present value (NPV) simulation of brand and generic manufacturing for new facilities is conducted comparing batch and continuous manufacturing processes leveraging actual industry financial revenue and cost information, and detailed engineering cost information of batch and CM manufacturing processes from a seminal manufacturing cost analysis of these two technologies.

Results When looking at comparing investment in either CM or batch for a new U.S. facility, the results clearly suggest that the lower costs associated with CM technology should lead to both brand and generic companies investing in the more CM manufacturing technology. The simulation analysis demonstrated that under current U.S. tax rates, investing in batch technology at U.S. sites would be economically more attractive than investing in batch technology in China or India. Investing in CM technology in the USA under current tax rates results in positive expected net NPVs over batch technology investments in China or India for both brand and generic companies. U.S. tax policy has a material impact on whether pharmaceutical companies would decide to invest on the USA or not for their manufacturing.

Conclusions Results indicate that continuous manufacturing has the potential to make manufacturing of OSD pharmaceuticals more economically attractive in the USA than foreign manufacturing of those products.
\end{abstract}

Keywords Pharmaceuticals $\cdot$ Continuous manufacturing $\cdot$ Manufacturing investment $\cdot$ Simulation

JEL Classification C63 $\cdot \mathrm{I} 11 \cdot \mathrm{I} 18 \cdot \mathrm{L} 65 \cdot \mathrm{O} 33$

\section{Introduction}

This study examines the economics associated with investing in one type of advanced manufacturing technology, continuous manufacturing $(\mathrm{CM})$, versus conventional batch manufacturing for production of oral solid dosage pharmaceutical (OSD) products in the USA and abroad. For decades, the pharmaceutical industry has relied on batch processing in the manufacture of OSD drug products. Advanced technologies such as CM have gained interest in recent years based in part on their potential to reduce manufacturing costs by

Clifford V. Rossi

crossi@umd.edu

1 Robert H. Smith School of Business, University of Maryland, 4465 Van Munching Hall, College Park, MD 20742, USA continuously processing inputs and materials throughout the development process. By contrast, batch processing is characterized by a sequence of steps that as described in more detail later can be inefficient and prone to more manual errors due to its more labor-intensive approach.

The provision of a continuous supply of affordable, safe, and effective pharmaceutical products, particularly those defined as "essential medicines" by the Food and Drug Administration (FDA) is a national imperative as evidenced by one of the first executive orders of the Biden administration to strengthen domestic supply chains [1]. For the most part, pharmaceutical products consumed in the USA have adhered to these expectations. However, considerable reliance on foreign pharmaceutical manufacturing that depends predominately on decades-old batch processing technology that is less automated and more difficult to scale production quickly raises serious concerns regarding the uninterrupted 
delivery of high-quality pharmaceutical products in the future. As of $2020,74 \%$ of all active pharmaceutical ingredients (APIs) and 54\% of all finished dosage form (FDF) human drug products were manufactured at facilities outside the USA [2].

A recall of the widely used blood thinning drug, heparin, in 2008 occurred due to an adulteration of the manufacturing process that introduced oversulfated chondroitin sulfate (OSCS) into batches of the product from a manufacturing facility in China and led to a large number of severe reactions to heparin in the USA and some deaths. While an isolated event, considering the vast numbers of OSD products manufactured each year, the heparin recall stands out as a cautionary tale for the importance of quality in pharmaceutical production.

Another persistent issue for the industry and the FDA has been drug shortages. Between 2013 and 2020, a total of 327 new drug shortages occurred and over the same period there were 553 ongoing drug shortages [3]. Casting additional light on the drug shortage issue was the COVID-19 pandemic which exposed shortages on $45 \%$ of the critical drugs used to combat the virus [4].

The U.S. Cybersecurity and Information Security Agency (CISA) has designated a number of industries as Critical Manufacturing Sectors deemed essential to the functioning of the U.S. economy. Pharmaceuticals are not listed as one of those sectors. Nevertheless, a significant reliance on foreign manufacturing of pharmaceutical products increases the risk of destabilizing the U.S. drug supply chain due to geopolitical and other forces and thus poses a long-term threat to U.S. consumers.

The pharmaceutical industry is characterized by divergent approaches to leveraging advanced technologies in R\&D and manufacturing segments of the business. Research and development activities in the pharmaceutical industry have driven remarkable advances in new drug products including biopharmaceuticals most recently evidenced by the stunning introduction of mRNA Covid vaccines. These products illustrate the industry's quick adoption of advanced science in pharmaceutical R\&D. Juxtaposed against pharmaceutical R\&D is a general tendency for the pharma industry's investment to lag in advanced manufacturing technologies. Drivers of this dichotomous technology investment strategy for the industry include a strong bias toward processes with longer industry track records and low-cost manufacturing solutions. Advanced manufacturing technologies such as CM have been implemented in only a small number of sites, and thus the industry has had far less experience with that technology's performance and cost than standard batch technology that exists at most manufacturing sites today in the USA and abroad.

A major contributing factor to pharmaceutical manufacturing outsourcing over the years includes a bifurcation between the brand and generic product markets where companies producing brand drugs enjoy product exclusivity over a long period of time that facilitates higher and more stable profit margins for that market segment compared to generic companies. The loss of exclusivity (LOE) poses much stiffer competition and an acute cost consciousness by generic companies faced with slimmer profit margins and greater sales volatility. For generics in particular, this market environment incents least cost manufacturing subject to FDA requirements on current good manufacturing practices (CGMP). Reinforcing this tendency have been the combined forces of increased scrutiny on drug pricing by policymakers and the consolidation and aggregation of pharmaceutical group purchasing organizations (GPOs) that create headwinds for pharma product pricing. Industry specialization in $R \& D$ and manufacturing has been facilitated by contract research organizations (CROs) and contract manufacturing organizations (CMOs) over the years underscores the costdriven nature of this sector.

Other factors at play in determining whether to manufacture pharmaceutical products in the USA or abroad include corporate taxes, differential labor and manufacturing costs, regulatory and environmental costs, and foreign exchange hedging expense. Differential costs of production have been widely referenced as a primary reason for the loss of U.S. manufacturing over the last several decades. The ascendancy of China as a major manufacturing hub over the years was accomplished in large measure by much lower labor, land, and capital costs as well as more relaxed environmental regulations. Wage and cost pressures over time, however, have reduced the China cost advantage in recent years to a slim $4 \%$ lower cost of manufacturing compared to the USA [6]. This shift in overall manufacturing competitiveness along with the potential of more automated technologies such as $\mathrm{CM}$ that require smaller plant footprints could encourage more pharmaceutical manufacturing in the USA. Alternatively, a more skilled labor force may be required to operate a CM facility which could lead to higher unit wage costs and training expenses initially. This analysis does not attempt to take these market dynamics into account due to a lack of data on this aspect of manufacturing cost.

Differential corporate tax rates are an important consideration by companies deciding whether and where to make a capital investment such as a manufacturing facility. In 2017, the Tax Cuts and Jobs Act reduced the U.S. marginal corporate tax rate from 35 to $21 \%$. This change put the USA in a more tax favorable position compared with China and India, for example, which imposes corporate tax rates of $25 \%$ and $30 \%$, respectively [7]. Consequently, understanding the sensitivity of investment in manufacturing facilities in the USA and overseas to potential changes in U.S. tax policy in light of new proposals to raise corporate tax rates is critical to developing a complete picture of the dynamics of the manufacturing investment problem. 
Regulation and environmental factors weigh in as additional nonfinancial considerations when selecting a manufacturing location. Inspection and oversight of pharmaceutical manufacturing is the responsibility of FDA. In 2019, the FDA conducted 1258 Drug Quality Surveillance inspections [8]. FDA conducts these inspections on a periodic basis using a risk-based methodology where facilities indicating a potential for higher risk are inspected more frequently. Costs associated with noncompliance of CGMP depend on the severity and frequency of the issue and include forcing companies to perform costly remediation of quality deficient processes, a potential for drug recalls, civil money penalties and fines, and profit garnishments [9]. The geographic distribution of facilities worldwide and limited staffing levels of FDA inspectors, along with country disparities in quality manufacturing, also poses long-term challenges for the agency. In addition to CGMP and other FDA regulations, environmental regulations in the USA tend to be more restrictive than in other parts of the world, including some large pharmaceutical manufacturing countries. These regulations can extend timelines for when manufacturing sites can commence operation, impose additional costs associated with the required use of environmentally friendly equipment, specify special training and requirements for disposal of chemicals and solvents used in the manufacturing process as well as levy penalties for an environmental hazard.

This study compares the net present value of new construction of continuous manufacturing facilities to new construction of batch manufacturing facilities for brand and generic companies operating in the USA and in select countries with large pharmaceutical manufacturing operations. Several hypotheses tested in the investment model are as follows:

- CM technology should generate higher NPVs than batch processing for brand companies in the USA due to higher and more stable profit margins making investments in such advanced technology economically attractive.

- Generic companies, due to less stable and lower profit margins, may find batch processing to be a more economically attractive U.S. manufacturing strategy.

- Investment in foreign batch manufacturing facilities may be more financially attractive than investment in U.S. batch manufacturing facilities due to lower costs abroad.

- Investment in CM manufacturing for brand companies at U.S.-based manufacturing facilities may be financially more attractive than investment in foreign manufacturing sites that rely on batch processing due to lower operating costs of CM even taking into account cost uncertainty with that technology.

A stochastic simulation of brand and generic manufacturing net present value (NPV) is performed. Operating and capital investment costs from a seminal engineering cost study comparing continuous and batch pharmaceutical manufacturing processes were used in the analysis along with historical revenues and other inputs of brand and generic pharmaceutical companies [10]. Revenues, operating, and capital costs were assumed to be stochastic variables in the model in order to develop a pharmaceutical manufacturing NPV distribution that examined expected NPV as well as probabilistically more extreme outcomes. More than 150 scenarios were tested among variations in manufacturing locations (USA, China, India, Ireland), product type (brand, generic), profit margin, foreign exchange hedge cost, and operating and capital cost volatility with 10,000 simulations conducted per scenario.

The results from the study indicate that in the USA, CM processes in almost all circumstances for both brand and generic companies result in higher NPVs than batch manufacturing processes, even under conservative $\mathrm{CM}$ cost volatility scenarios. U.S. CM process scenarios generate higher NPVs than batch processing scenarios in China and India for the majority of scenarios. Only in Ireland, which enjoys a significantly lower corporate tax rate $(12.5 \%)$ than the USA, does $\mathrm{CM}$ underperform batch manufacturing in terms of NPV along most scenarios. The results suggest that investment in CM processes in the USA by both brand and generic companies would not only result in higher NPVs over standard batch processing in the USA but result in higher NPVs over those associated with new batch facilities in either China or India under current U.S. corporate tax rates.

The results of these simulations, however, do not explain the industry's relatively slow adoption of CM technology in OSD manufacturing. On one hand, the results for brand companies are entirely consistent with the composition of firms that have engaged with the FDA's Emerging Technology Program (ETP) to develop CM-based manufacturing capabilities. The firms involved in this program tend to be large brand producing companies. Other factors must explain why generic and brand companies overall are not yet attracted to CM technology investment at any scale of operation given the results of this study. Part of the answer appears to be due to significant embedded costs of existing batch technology investments reflected in large undepreciated accounts. Retrofitting existing manufacturing facilities to CM-based operations would add substantial near-term costs that over the long-run with depreciation would become more attractive financially. Other factors may include a lack of advanced skill sets and/or experience with CM technology along with cost and regulatory uncertainty. The latter issue is outside the scope of this analysis due to a lack of available information to reliably assess their impact on CM technology investment. However, cost uncertainty associated with CM manufacturing is incorporated in the simulation analysis via a set of stochastic cost variables. 
From a public policy perspective, a number of factors warrant consideration as to whether and to what extent incentives for advanced manufacturing technologies should be provided to the pharmaceutical industry. President Biden signed an Executive Order on America's Supply Chains on February 24, 2021, calling on agencies to review the risks associated with certain designated critical supply chains including those for pharmaceuticals. Included in this Executive Order is a review of public and private incentives to encourage investment in production of "critical goods and materials." National interest or national security issues have been cited as reasons why certain industries or products merit some form of protection by way of risk mitigation strategies, information/ research advantages or financial and/or tax incentives, among others. In the case of pharmaceutical manufacturing, an argument could be made for a policy aimed at raising the level of domestic production of pharmaceuticals in the USA through a variety of financial and nonfinancial measures. These could range from acceleration of private-public partnerships to serve as manufacturing labs for testing the feasibility of CM processes, broadening access to federal technology resources and reducing regulatory requirements to the industry for accelerating $\mathrm{CM}$ development, to direct and indirect subsidies such as tax credits for eligible companies. Tradeoffs to consider in deciding what policy prescriptions should be leveraged include identifying root causes for the relative lack of industry investment, and the potential need for direct or indirect financial and nonfinancial support. Addressing domestic manufacturing with industrial policies that are designed to facilitate growth in some sector of production due to some observed or perceived market failure has been subject to much debate among economists over the years. Much of the criticism argues that government intervention in this case creates market inefficiencies and distortions that are better left to market forces to determine. Nevertheless, identifying industry barriers to domestic and advanced technology pharmaceutical manufacturing investment will at least help establish what type of policies may be most effective at stimulating such investments. versus CM manufacturing. A NPV analysis is a standard methodology used in determining whether a potential investment is economically viable or not. For a project with a projected lifespan of $N$ years, its NPV is calculated as below:

$\mathrm{NPV}=\sum_{n=0}^{N} \frac{\left(\mathrm{CFI}_{n}-\mathrm{CFO}_{n}\right)}{(1+r)^{n}}-I_{0}$

where $\mathrm{CFI}_{n}$ and $\mathrm{CFO}_{n}$ represent cash inflows and outflows, respectively, $r$ is the required rate of return or discount rate, and $I_{0}$ represents the initial investment cost. This static representation of NPV characterizes the investment decision along a single path of cash flows. However, a more realistic view of cash inflows, outflows, and investment costs would incorporate some form of variability in cash flows and costs over many possible outcomes.

In the following analysis, we assume pharmaceutical companies are risk-averse and their utility functions follow von Neumann-Morgenstern axioms under uncertainty. Pharmaceutical manufacturers are further assumed to produce brand or generic drugs based on a twice differentiable continuous production function using manufacturing and nonmanufacturing inputs $x_{M}$ and $x_{N M}$, respectively. Manufacturing efficiency is in turn a function of technology $(\varphi$ $(\alpha)$ ) represented by a vector of batch and $\mathrm{CM}$ engineering and process-related factors $\alpha$ where $0<\alpha<1$. The production function is thus characterized as follows:

$q=f\left(\varphi(\alpha) x_{M}, x_{N M}\right)$

The objective of the pharmaceutical manufacturer is to maximize expected utility of profit $(\omega)(U(\omega))$, where $U(\omega)$ is the von Neumann-Morgenstern utility function, a standard assumption in economics for production under uncertainty. This approach is comparable to Lakdawalla's characterization of the optimal investment in pharmaceutical research and development [11]. In the theoretical model of a pharmaceutical manufacturer, uncertainty is introduced in the form of three stochastic variables; pharmaceutical sales (production), $\mathrm{CM}$ technology operating costs, and initial investment costs of CM technology. The generalized form of the pharmaceutical manufacturer's objective function is the following:

$\left.\operatorname{Max} E\{U(\omega)\}=\operatorname{Max} \int\left\{\left(U\left(p f\left(\varepsilon_{P}, \varphi(\alpha) x_{M}, x_{N M}\right) d \theta_{P}-g\left(\varepsilon_{M}, r_{M} x_{M} \Delta_{i}\right) d \theta_{M}\left(\varepsilon_{M}\right)-r_{N M} x_{N M}-h c\right)-j\left(\varepsilon_{I}, I \Delta_{i}\right) d \theta_{I}\left(\varepsilon_{I}\right)\right)\right)\left(1-\operatorname{MTR}_{i}\right)\right\}\left(\varepsilon_{P}\right)$

\section{A Theoretical Model of Pharmaceutical Manufacturing Investment}

To better understand the economics and risks associated with investing in advanced manufacturing processes by pharmaceutical companies, a multi-period empirical analysis is performed comparing investment strategies in batch where

- $p=$ OSD price per unit

- $\varepsilon_{P}=$ a random variable for production risk associated with the OSD manufacturing process with distribution $\Theta_{P}$

- $\varepsilon_{M}$ and $\varepsilon_{I}=$ random variables for manufacturing costs and capital investment, with distributions $\Theta_{M}$ and $\Theta_{I}$, respectively 
- $r_{M}$ and $r_{N M}$ represent input costs for manufacturing and nonmanufacturing inputs, respectively

- $\Delta_{I}=$ country $I$ manufacturing cost competitiveness factor

- $h c=$ foreign exchange hedging costs

- $\mathrm{MTR}_{i}=$ marginal corporate tax rate of country $i$

- $I=$ capital investment cost at time 0

A pharmaceutical manufacturer is further assumed to decide whether to invest in CM technology in the USA or use batch technology in either the USA or abroad. CM technology is assumed to be more efficient and thus increase pharmaceutical manufacturing productivity such that $\varphi\left(\alpha_{C M}\right)>\varphi\left(\alpha_{\text {Batch }}\right)$. The parameterization of these productivity factors leverages a cost study of $\mathrm{CM}$ versus batch processing for a new OSD facility described in more detail below. According to this construct, a pharmaceutical company will adopt the advanced CM manufacturing technology whenever the following holds:

$E\left\{U\left(\omega_{C M}\right)\right\}-E\left\{U\left(\omega_{\text {Batch }}\right)\right\}>0$

For the CM and batch technology scenarios, this can be represented in terms of a firm's objective function as follows: inputs of interest include the estimated operating and capital costs associated with batch production along with the study's estimates of cost factors associated with $\mathrm{CM}$ technology. Specifically, the Schaber et al. estimates of \$226 M and \$346 M for a new facility's batch processing operating and capital costs, respectively are used [10]. Moreover, for $\mathrm{CM}$ operating and capital costs, the cost factors from the Schaber et al. study are used for those components associated with their CM process that uses a single recycling loop which provides a higher quality $\mathrm{CM}$ process according to the study's authors [10]. Operating costs in the study considered labor, material handling, utilities, waste disposal as well as QA/QC expenses. A $10 \%$ premium on CM equipment was imposed by Schaber et al. to account for additional process engineering expense. Applying the Schaber et al. CM operating and capital cost efficiency factors of $-20 \%$ and $-33 \%$ which they derived from detailed cost analysis of batch and $\mathrm{CM}$ processes, respectively to the batch process dollar cost estimates above translated into CM operating and capital costs of approximately $\$ 181 \mathrm{M}$ and $\$ 232 \mathrm{M}$, respectively.

The Schaber et al. study is noteworthy for its findings that $\mathrm{CM}$ processes generated discounted costs that were 9 to $40 \%$ lower than batch processing depending on the API mass loading, key ingredient cost, and CM technology sce-

$\left.\operatorname{Max} \int\left\{\left(U\left(p f\left(\varepsilon_{P}, \varphi\left(\omega^{C M}\right) x_{M}^{C M}, x_{N M}\right) d \theta_{P}\left(\varepsilon_{P}\right)-g\left(\varepsilon_{M}, r_{M}^{C M} x_{M}^{C M} \Delta_{i}\right) d \theta_{M}\left(\varepsilon_{M}\right)-r_{N M} x_{N M}-h c\right)-j\left(\varepsilon_{I}, I^{C M} \Delta_{i}\right) d \theta_{I}\left(\varepsilon_{I}\right)\right)\right)\left(1-\mathrm{MTR}_{i}\right)\right\}\left(\varepsilon_{P}\right)$

$\left.\operatorname{Max} \int\left\{\left(U\left(p f\left(\varepsilon_{P}, \varphi\left(\omega^{\text {Batch }}\right) x_{M}^{\text {Batch }}, x_{N M}\right) d \theta_{P}\left(\varepsilon_{P}\right)-g\left(\varepsilon_{M}, r_{M}^{\text {Batch }} x_{M}^{\text {Batch }} \Delta_{i}\right) d \theta_{M}\left(\varepsilon_{M}\right)-r_{N M} x_{N M}-h c\right)-j\left(\varepsilon_{I}, I^{\text {Batch }} \Delta_{i}\right) d \theta_{I}\left(\varepsilon_{I}\right)\right)\right)\left(1-M T R_{i}\right)\right\}\left(\varepsilon_{P}\right)$

\section{Methodology, Model Parametrization, and Assumptions}

Implementation of the theoretical model requires specific information of the costs and approximate relative efficiencies of batch and CM pharmaceutical manufacturing technology. As a result, the empirical analysis is dependent on the availability and reliability of such information. The analysis is confined to manufacturing of OSD products using CM or batch technology based on an important study of CM and batch costs by FDA, Current Good Manufacturing Practice (CGMP) Regulations [9].

Schaber et al. undertook a study to compare the discounted costs associated with $\mathrm{CM}$ versus batch technology for a representative OSD product. The analysis focused on comparing costs between $\mathrm{CM}$ and batch processes for a "high-volume" production scale of 2000 tons of tablets per year. The study provided engineering-based estimates of various inputs of production such as raw materials along with detailed operating and capital cost estimates. The results from the Schaber et al. study are used for this analysis. The nario used. In the case of the $\mathrm{CM}$ with recycling scenario assuming, the $\$ 500 / \mathrm{kg}$ key ingredient cost and 10\% API mass loading scenario, discounted costs of CM were $22 \%$ lower than batch. Despite the analytic rigor associated with the Schaber et al. study, the results have come under some scrutiny. Manning and Sciacca, for example, contend that study relied more on expert judgment in developing estimates rather than on empirical observations [12]. With a paucity of publicly available data on CM costs, the expert judgment approach taken by Schaber et al. is entirely consistent with discounted cost analysis conducted extensively by organizations for a wide range of engineering-intensive investment projects. To be sure, the study does have other limitations that may reduce the significance of the findings. Two of the most significant limitations are that the study focuses only on costs and presents the model in a deterministic framework. By focusing only on manufacturing costs, the Schaber et al. study ignores the impact of cash inflows on the investment decision. As discussed earlier, this can be a significant factor in whether a company chooses to invest in $\mathrm{CM}$ or not. Pricing and competition in brand and generic 
markets could make the difference between the type of firms likely to adopt CM technology over batch manufacturing processes. Furthermore, any such study of advanced manufacturing should take into account the distribution of potential cash flows in producing pharmaceuticals. Nor does the Schaber et al. study address U.S. versus non-U.S investment decisions. As a result, this study offers the first stochastic NPV simulation comparing CM to batch technology for pharmaceutical manufacturing. The study focuses only on new construction and not plant retrofit as a scenario. It also assumes the same large scale of production assumed in the Schaber et al. study. With additional data and information on $\mathrm{CM}$ costs for smaller scale production and retrofit costs, this model could easily be extended in the future to handle those scenarios.

The definition used for NPV in the model is as follows: calculation for TOC for company type $k$ (brand or generic) and manufacturing type $\alpha$ (CM or batch) used is as follows:

$\mathrm{TOC}_{\alpha}^{k}=\frac{\operatorname{MOp} E x_{\alpha}}{\operatorname{COGS} \%^{k}}$

Revenue for the model was derived as follows:

Revenue $_{\alpha}^{k}=\frac{\mathrm{TOC}_{\alpha}^{k}}{P M^{k}}$

In this formula, PM represents the historical profit margin (in percent) for company $k$. NPV revenue, cost, and discount rate inputs used in the analysis are shown in Table 1. Discount rates were generated from WRDS historical data.

The three stochastic variables in the model; revenue, MOpEx, and MCapEx were assumed to follow a general-

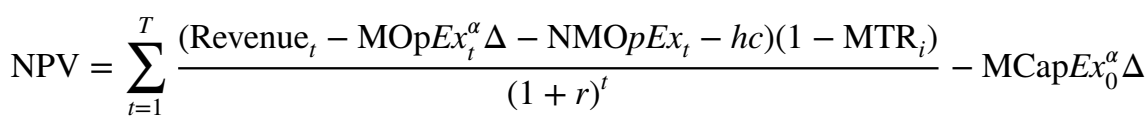

where

- Revenue represents annual sales of the pharmaceutical OSD product

- MOpEx is manufacturing operating expense for technology $\alpha$ (i.e., batch or CM)

- NMOpex is nonmanufacturing annual costs

- hc represents foreign exchange hedging costs

- MTR is the marginal corporate tax rate for country $i$

- MCapEx is the capital cost associated with technology $\alpha$ for country $i$

- $r$ is the discount rate

Two additional assumptions in the analysis included the project time horizon and brand loss of exclusivity period. The Schaber et al. study assumed a 15 -year project horizon; however, this is likely to be much smaller than the actual lifecycle for a new drug [11]. For this analysis, a 20-year horizon was applied. The analysis also assumed that LOE occurred after the $12^{\text {th }}$ year of the analysis. This estimate is based on a number of studies cited by Kesselheim et al. that estimated LOE periods for various drug products over time [13].

In order to align the Schaber et al. study cost estimates for batch and CM manufacturing processes with actual pharmaceutical industry financial structure information, revenues and nonmanufacturing costs were scaled to be consistent with the WRDS data for brand and generic company historical profit margin. To derive these components of NPV for the model, total operating cost (TOC) for brand and generic companies was computed based on the average of historical cost of goods sold (COGS) as a percent of TOC. The ized Weiner process with a constant drift rate and variance. The discrete form of each stochastic variable is represented by the following:

$\frac{\Delta V}{V}=\mu \Delta t+\sigma \epsilon \sqrt{\Delta t}$

$\Delta V=\mu V \Delta t+\sigma V \epsilon \sqrt{\Delta t}$

where $\mu$ is the drift rate, $\sigma$ is the standard deviation (volatility) of variable $V$ and $\varepsilon$ is a random normal variable. It is assumed, following convention with other cost studies, that operating, and capital costs are lognormally rather than normally distributed as are revenues [14]. The lognormal distribution ensures nonnegative costs and revenues and also better reflects the tendency that costs are more likely to go up than down. It can be shown that if a random variable $y$ is a function of $x$ or $y=y(x)$, then the probability density function of $y$ and $x$ is the following:

Table 1 Model NPV inputs

\begin{tabular}{lll}
\hline NPV component & Brand company & Generic company \\
\hline $\begin{array}{l}\text { Revenue }(\$ M) \\
\text { MOpEx }(\$ M)\end{array}$ & $\$ 1569$ & $\$ 813$ \\
CM & $\$ 181$ & $\$ 181$ \\
$\quad$ Batch & $\$ 226$ & $\$ 226$ \\
NMOpEx (\$M) & $\$ 910$ & $\$ 439$ \\
MCapEx (\$M) & & \\
CM & $\$ 232$ & $\$ 232$ \\
Batch & $\$ 346$ & $\$ 346$ \\
Discount rate $(\%)$ & 6.76 & 6.14 \\
\hline
\end{tabular}


$f(y)=f(x) \frac{d x}{d y}$

And if $x$ follows a normal distribution, then $y=e^{X}$ is lognormally distributed. In order to generate lognormal distribution for costs and revenues, we need to generate a lognormal random variable. The process used was to generate 10,000 standard normal random variates $Z$. By letting $x=\mu+\sigma Z$ where $\mu$ and $\sigma$ are parameters of the lognormally distributed random variable over 10,000 simulations we can generate $y$, a lognormally distributed variable. The simulation process thus entailed generating separate lognormal distributions of revenues and costs for the different technology outcomes. To align the USA and non-U.S. technology outcomes, we generated the non-U.S. outcome sales and cost distributions by applying the same random variables used in the U.S. outcome. Then, the NPVs were computed for each of the 10,000 trials to generate a distribution for the batch and CM technology outcomes.

For the analysis, $\mu$ is set at 0 . The long-term drift in revenues and manufacturing costs would affect nominal NPV, but since we are interested ultimately in net NPV between $\mathrm{CM}$ and batch technologies, this assumption has no effect on the result of interest, namely the net NPV of CM and batch scenarios. Estimates for revenue volatility, however, are developed from the historical WRDS data. For brand and generic companies, the estimates used in the model for annual revenue volatility were $7.1 \%$ and $27.5 \%$, respectively. A baseline annual volatility for manufacturing operating and capital cost was set at $2.5 \%$ based on a study by Achilleos et al. [15]. For each scenario, 10,000 simulated NPVs were generated in order to obtain a reasonably shaped distribution, particularly the left-hand (negative NPV) tail of the distribution. A total of 156 different scenarios were run on combinations of the following attributes:

- Company type (brand/generic)

- Manufacturing type (CM/batch)

- Country (USA/India/Ireland/China)

- CM cost volatility $(2.5 \% / 10 \% / 15 \%)$

- Profit margin volatility

- Brand 15\% (year. 1-12)/10\% (years 13-20)

- Brand 10\% (year. 1-12)/5\% (years 13-20)

- Brand 5\% (years 1-12)/0\% (year. 13-20)

- Generic (10\%/5\%/0\% years $1-20)$

- US tax rate $(21 \% / 28 \%)$

- Foreign exchange hedging cost variability $(1 \%, 2 \%, 4 \%)$

Note that for the brand company scenarios, an assumption is made to switch over to generic revenues starting in year 13 reflecting a loss of exclusivity. The specific scenarios for brand and generic companies tested are found in Tables 2 and 3 . The $10 \%$ and $15 \% \mathrm{CM}$ cost volatility scenarios as well as the profit margin and foreign exchange hedge cost scenarios were intended for sensitivity analysis of the results to key NPV drivers. Other key model inputs included comparative manufacturing productivity rates for China, India, and Ireland and corporate tax rates for these countries. Table 4 provides details on these inputs. All hedge costs scenarios assumed currency risk was fully hedged but the cost associated with buying and selling hedge instruments varied from $0 \%$ (baseline) to $4 \%$.

Each of the 156 scenarios compare a baseline (e.g., U.S. $\mathrm{CM}$ ) to a challenger country/technology alternative (e.g., China/batch). While the entire distribution of NPVs is generated for the baseline and alternative, this study is most interested in the expected NPV (E(NPV))as well as two measures of NPV tail risk: the $95^{\text {th }}$ and $99^{\text {th }}$ worst (lowest) NPVs among the 10,000 simulated NPV values for each scenario. In a stochastic NPV simulation, $E(\mathrm{NPV})$ is useful as it provides a more robust estimate of a project's financial prospects than a single deterministic path assessment. However, making a business decision on a costly project should also consider the risk of that project as depicted in the tail of the distribution. In the financial services industry, for example, value-at-risk, or VaR is a way of measuring the risk of a decline in value of a bank's trading book over some period of time (e.g., 1 day). A bank will generate a distribution of the end of trading day portfolio value and compare that value to some board-approved VaR. For example, assume that the risk office of a bank has looked at historical portfolio values and found that the $99^{\text {th }}$ percentile worst daily portfolio trading loss was \$1billion and the board sets this as the 1-day VaR for the bank. This would mean that the 99 percentile worst allowable loss over a single day would be $\$ 1$ billion and the bank would hold additional capital to guard against that loss.

A variation of this VaR concept can be leveraged in the case of pharmaceutical manufacturing investment decisions by comparing the distributions of net NPV for the baseline and country/technology alternative and using a percentile of the lowest net NPV as an investment VaR. Figure 1 describes the application of project investment VaR in this study. For a particular scenario, NPV distributions for the country/ technology baseline and alternative are generated (panels A and B). The difference, referred to as net NPV across each of the 10,000 trials for each scenario (e.g., [US CM - U.S. Batch] NPV), is depicted in panel C. If a company wanted to be $99 \%$ confident that an investment in CM technology would result in a higher NPV than batch, then they would select $X$ as their target net NPV VaR and base their decision on that selection. If in running a scenario, the net NPV was to the left of the $99^{\text {th }}$ percentile target then the project would be less desirable. Note that the company can select any 
Table 2 Brand company NPV scenarios

\begin{tabular}{|c|c|c|c|c|c|c|}
\hline Scenario & Baseline & Comparison & CM cost volatility & Profit margin volatility & Hedge cost & US Tax Rate \\
\hline 1 & US Batch & US CM & $2.50 \%$ & 0 & 0 & $21 \%$ \\
\hline 2 & US Batch & US CM & $10 \%$ & 0 & 0 & $21 \%$ \\
\hline 3 & US Batch & US CM & $15 \%$ & 0 & 0 & $21 \%$ \\
\hline 4 & US Batch & US CM & $2.50 \%$ & $15 \%($ year $1-12) / 10 \%$ (years $13-20$ ) & 0 & $21 \%$ \\
\hline 5 & US Batch & US CM & $2.50 \%$ & $10 \%($ year $1-12) / 5 \%($ years $13-20)$ & 0 & $21 \%$ \\
\hline 6 & US Batch & US CM & $2.50 \%$ & $5 \%$ (years $1-12) / 0 \%$ (years $13-20$ ) & 0 & $21 \%$ \\
\hline 7 & US CM & China batch & $2.50 \%$ & $0 \%$ & $1 \%$ & $21 \%$ \\
\hline 8 & US CM & China batch & $2.50 \%$ & $0 \%$ & $2 \%$ & $21 \%$ \\
\hline 9 & US CM & China batch & $2.50 \%$ & $0 \%$ & $4 \%$ & $21 \%$ \\
\hline 10 & US CM & China batch & $10.00 \%$ & $0 \%$ & $1 \%$ & $21 \%$ \\
\hline 11 & US CM & China batch & $10.00 \%$ & $0 \%$ & $2 \%$ & $21 \%$ \\
\hline 12 & US CM & China batch & $10.00 \%$ & $0 \%$ & $4 \%$ & $21 \%$ \\
\hline 13 & US CM & China batch & $15.00 \%$ & $0 \%$ & $1 \%$ & $21 \%$ \\
\hline 14 & US CM & China batch & $15.00 \%$ & $0 \%$ & $2 \%$ & $21 \%$ \\
\hline 15 & US CM & China batch & $15.00 \%$ & $0 \%$ & $4 \%$ & $21 \%$ \\
\hline 16 & US CM & China batch & $2.50 \%$ & $0 \%$ & $1 \%$ & $28 \%$ \\
\hline 17 & US CM & China batch & $2.50 \%$ & $0 \%$ & $2 \%$ & $28 \%$ \\
\hline 18 & US CM & China batch & $2.50 \%$ & $0 \%$ & $4 \%$ & $28 \%$ \\
\hline 19 & US CM & China batch & $10.00 \%$ & $0 \%$ & $1 \%$ & $28 \%$ \\
\hline 20 & US CM & China batch & $10.00 \%$ & $0 \%$ & $2 \%$ & $28 \%$ \\
\hline 21 & US CM & China batch & $10.00 \%$ & $0 \%$ & $4 \%$ & $28 \%$ \\
\hline 22 & US CM & China batch & $15.00 \%$ & $0 \%$ & $1 \%$ & $28 \%$ \\
\hline 23 & US CM & China batch & $15.00 \%$ & $0 \%$ & $2 \%$ & $28 \%$ \\
\hline 24 & US CM & China batch & $15.00 \%$ & $0 \%$ & $4 \%$ & $28 \%$ \\
\hline 25 & US batch & China batch & $2.50 \%$ & $0 \%$ & $1 \%$ & $21 \%$ \\
\hline 26 & US batch & China batch & $2.50 \%$ & $0 \%$ & $2 \%$ & $21 \%$ \\
\hline 27 & US batch & China batch & $2.50 \%$ & $0 \%$ & $4 \%$ & $21 \%$ \\
\hline 28 & US batch & China batch & $2.50 \%$ & $0 \%$ & $1 \%$ & $28 \%$ \\
\hline 29 & US batch & China batch & $2.50 \%$ & $0 \%$ & $2 \%$ & $28 \%$ \\
\hline 30 & US batch & China batch & $2.50 \%$ & $0 \%$ & $4 \%$ & $28 \%$ \\
\hline 31 & US CM & India batch & $2.50 \%$ & $0 \%$ & $1 \%$ & $21 \%$ \\
\hline 32 & US CM & India batch & $2.50 \%$ & $0 \%$ & $2 \%$ & $21 \%$ \\
\hline 33 & US CM & India batch & $2.50 \%$ & $0 \%$ & $4 \%$ & $21 \%$ \\
\hline 34 & US CM & India batch & $10.00 \%$ & $0 \%$ & $1 \%$ & $21 \%$ \\
\hline 35 & US CM & India batch & $10.00 \%$ & $0 \%$ & $2 \%$ & $21 \%$ \\
\hline 36 & US CM & India batch & $10.00 \%$ & $0 \%$ & $4 \%$ & $21 \%$ \\
\hline 37 & US CM & India batch & $15.00 \%$ & $0 \%$ & $1 \%$ & $21 \%$ \\
\hline 38 & US CM & India batch & $15.00 \%$ & $0 \%$ & $2 \%$ & $21 \%$ \\
\hline 39 & US CM & India batch & $15.00 \%$ & $0 \%$ & $4 \%$ & $21 \%$ \\
\hline 40 & US CM & India batch & $2.50 \%$ & $0 \%$ & $1 \%$ & $28 \%$ \\
\hline 41 & US CM & India batch & $2.50 \%$ & $0 \%$ & $2 \%$ & $28 \%$ \\
\hline 42 & US CM & India batch & $2.50 \%$ & $0 \%$ & $4 \%$ & $28 \%$ \\
\hline 43 & US CM & India batch & $10.00 \%$ & $0 \%$ & $1 \%$ & $28 \%$ \\
\hline
\end{tabular}


Table 2 (continued)

\begin{tabular}{|c|c|c|c|c|c|c|}
\hline Scenario & Baseline & Comparison & CM cost volatility & Profit margin volatility & Hedge cost & US Tax Rate \\
\hline 44 & US CM & India batch & $10.00 \%$ & $0 \%$ & $2 \%$ & $28 \%$ \\
\hline 45 & US CM & India batch & $10.00 \%$ & $0 \%$ & $4 \%$ & $28 \%$ \\
\hline 46 & US CM & India batch & $15.00 \%$ & $0 \%$ & $1 \%$ & $28 \%$ \\
\hline 47 & US CM & India batch & $15.00 \%$ & $0 \%$ & $2 \%$ & $28 \%$ \\
\hline 48 & US CM & India batch & $15.00 \%$ & $0 \%$ & $4 \%$ & $28 \%$ \\
\hline 49 & US batch & India batch & $2.50 \%$ & $0 \%$ & $1 \%$ & $21 \%$ \\
\hline 50 & US batch & India batch & $2.50 \%$ & $0 \%$ & $2 \%$ & $21 \%$ \\
\hline 51 & US batch & India batch & $2.50 \%$ & $0 \%$ & $4 \%$ & $21 \%$ \\
\hline 52 & US batch & India batch & $2.50 \%$ & $0 \%$ & $1 \%$ & $28 \%$ \\
\hline 53 & US batch & India batch & $2.50 \%$ & $0 \%$ & $2 \%$ & $28 \%$ \\
\hline 54 & US batch & India batch & $2.50 \%$ & $0 \%$ & $4 \%$ & $28 \%$ \\
\hline 55 & US CM & Ireland batch & $2.50 \%$ & $0 \%$ & $1 \%$ & $21 \%$ \\
\hline 56 & US CM & Ireland batch & $2.50 \%$ & $0 \%$ & $2 \%$ & $21 \%$ \\
\hline 57 & US CM & Ireland batch & $2.50 \%$ & $0 \%$ & $4 \%$ & $21 \%$ \\
\hline 58 & US CM & Ireland batch & $10.00 \%$ & $0 \%$ & $1 \%$ & $21 \%$ \\
\hline 59 & US CM & Ireland batch & $10.00 \%$ & $0 \%$ & $2 \%$ & $21 \%$ \\
\hline 60 & US CM & Ireland batch & $10.00 \%$ & $0 \%$ & $4 \%$ & $21 \%$ \\
\hline 61 & US CM & Ireland batch & $15.00 \%$ & $0 \%$ & $1 \%$ & $21 \%$ \\
\hline 62 & US CM & Ireland batch & $15.00 \%$ & $0 \%$ & $2 \%$ & $21 \%$ \\
\hline 63 & US CM & Ireland batch & $15.00 \%$ & $0 \%$ & $4 \%$ & $21 \%$ \\
\hline 64 & US CM & Ireland batch & $2.50 \%$ & $0 \%$ & $1 \%$ & $28 \%$ \\
\hline 65 & US CM & Ireland batch & $2.50 \%$ & $0 \%$ & $2 \%$ & $28 \%$ \\
\hline 66 & US CM & Ireland batch & $2.50 \%$ & $0 \%$ & $4 \%$ & $28 \%$ \\
\hline 67 & US CM & Ireland batch & $10.00 \%$ & $0 \%$ & $1 \%$ & $28 \%$ \\
\hline 68 & US CM & Ireland batch & $10.00 \%$ & $0 \%$ & $2 \%$ & $28 \%$ \\
\hline 69 & US CM & Ireland batch & $10.00 \%$ & $0 \%$ & $4 \%$ & $28 \%$ \\
\hline 70 & US CM & Ireland batch & $15.00 \%$ & $0 \%$ & $1 \%$ & $28 \%$ \\
\hline 71 & US CM & Ireland batch & $15.00 \%$ & $0 \%$ & $2 \%$ & $28 \%$ \\
\hline 72 & US CM & Ireland batch & $15.00 \%$ & $0 \%$ & $4 \%$ & $28 \%$ \\
\hline 73 & US batch & Ireland batch & $2.50 \%$ & $0 \%$ & $1 \%$ & $21 \%$ \\
\hline 74 & US batch & Ireland batch & $2.50 \%$ & $0 \%$ & $2 \%$ & $21 \%$ \\
\hline 75 & US batch & Ireland batch & $2.50 \%$ & $0 \%$ & $4 \%$ & $21 \%$ \\
\hline 76 & US batch & Ireland batch & $2.50 \%$ & $0 \%$ & $1 \%$ & $28 \%$ \\
\hline 77 & US batch & Ireland batch & $2.50 \%$ & $0 \%$ & $2 \%$ & $28 \%$ \\
\hline 78 & US batch & Ireland batch & $2.50 \%$ & $0 \%$ & $4 \%$ & $28 \%$ \\
\hline
\end{tabular}


Table 3 Generic company NPV scenarios

\begin{tabular}{|c|c|c|c|c|c|c|}
\hline Scenario & Baseline & Comparison & $\mathrm{CM}$ cost volatility & Profit margin volatility & Hedge cost & US tax rate \\
\hline 1 & US batch & US CM & $2.50 \%$ & 0 & 0 & $21 \%$ \\
\hline 2 & US batch & US CM & $10 \%$ & 0 & 0 & $21 \%$ \\
\hline 3 & US batch & US CM & $15 \%$ & 0 & 0 & $21 \%$ \\
\hline 4 & US batch & US CM & $2.50 \%$ & $10 \%$ (years $1-20$ ) & 0 & $21 \%$ \\
\hline 5 & US batch & US CM & $2.50 \%$ & $5 \%($ years $1-20)$ & 0 & $21 \%$ \\
\hline 6 & US batch & US CM & $2.50 \%$ & $0 \%$ (years $1-20)$ & 0 & $21 \%$ \\
\hline 7 & US CM & China batch & $2.50 \%$ & $0 \%$ & $1 \%$ & $21 \%$ \\
\hline 8 & US CM & China batch & $2.50 \%$ & $0 \%$ & $2 \%$ & $21 \%$ \\
\hline 9 & US CM & China batch & $2.50 \%$ & $0 \%$ & $4 \%$ & $21 \%$ \\
\hline 10 & US CM & China batch & $10.00 \%$ & $0 \%$ & $1 \%$ & $21 \%$ \\
\hline 11 & US CM & China batch & $10.00 \%$ & $0 \%$ & $2 \%$ & $21 \%$ \\
\hline 12 & US CM & China batch & $10.00 \%$ & $0 \%$ & $4 \%$ & $21 \%$ \\
\hline 13 & US CM & China batch & $15.00 \%$ & $0 \%$ & $1 \%$ & $21 \%$ \\
\hline 14 & US CM & China batch & $15.00 \%$ & $0 \%$ & $2 \%$ & $21 \%$ \\
\hline 15 & US CM & China batch & $15.00 \%$ & $0 \%$ & $4 \%$ & $21 \%$ \\
\hline 16 & US CM & China batch & $2.50 \%$ & $0 \%$ & $1 \%$ & $28 \%$ \\
\hline 17 & US CM & China batch & $2.50 \%$ & $0 \%$ & $2 \%$ & $28 \%$ \\
\hline 18 & US CM & China batch & $2.50 \%$ & $0 \%$ & $4 \%$ & $28 \%$ \\
\hline 19 & US CM & China batch & $10.00 \%$ & $0 \%$ & $1 \%$ & $28 \%$ \\
\hline 20 & US CM & China batch & $10.00 \%$ & $0 \%$ & $2 \%$ & $28 \%$ \\
\hline 21 & US CM & China batch & $10.00 \%$ & $0 \%$ & $4 \%$ & $28 \%$ \\
\hline 22 & US CM & China batch & $15.00 \%$ & $0 \%$ & $1 \%$ & $28 \%$ \\
\hline 23 & US CM & China batch & $15.00 \%$ & $0 \%$ & $2 \%$ & $28 \%$ \\
\hline 24 & US CM & China batch & $15.00 \%$ & $0 \%$ & $4 \%$ & $28 \%$ \\
\hline 25 & US batch & China batch & $2.50 \%$ & $0 \%$ & $1 \%$ & $21 \%$ \\
\hline 26 & US batch & China batch & $2.50 \%$ & $0 \%$ & $2 \%$ & $21 \%$ \\
\hline 27 & US batch & China batch & $2.50 \%$ & $0 \%$ & $4 \%$ & $21 \%$ \\
\hline 28 & US batch & China batch & $2.50 \%$ & $0 \%$ & $1 \%$ & $28 \%$ \\
\hline 29 & US batch & China batch & $2.50 \%$ & $0 \%$ & $2 \%$ & $28 \%$ \\
\hline 30 & US batch & China batch & $2.50 \%$ & $0 \%$ & $4 \%$ & $28 \%$ \\
\hline 31 & US CM & India batch & $2.50 \%$ & $0 \%$ & $1 \%$ & $21 \%$ \\
\hline 32 & US CM & India batch & $2.50 \%$ & $0 \%$ & $2 \%$ & $21 \%$ \\
\hline 33 & US CM & India batch & $2.50 \%$ & $0 \%$ & $4 \%$ & $21 \%$ \\
\hline 34 & US CM & India batch & $10.00 \%$ & $0 \%$ & $1 \%$ & $21 \%$ \\
\hline 35 & US CM & India batch & $10.00 \%$ & $0 \%$ & $2 \%$ & $21 \%$ \\
\hline 36 & US CM & India batch & $10.00 \%$ & $0 \%$ & $4 \%$ & $21 \%$ \\
\hline 37 & US CM & India batch & $15.00 \%$ & $0 \%$ & $1 \%$ & $21 \%$ \\
\hline 38 & US CM & India batch & $15.00 \%$ & $0 \%$ & $2 \%$ & $21 \%$ \\
\hline 39 & US CM & India batch & $15.00 \%$ & $0 \%$ & $4 \%$ & $21 \%$ \\
\hline 40 & US CM & India batch & $2.50 \%$ & $0 \%$ & $1 \%$ & $28 \%$ \\
\hline 41 & US CM & India batch & $2.50 \%$ & $0 \%$ & $2 \%$ & $28 \%$ \\
\hline 42 & US CM & India batch & $2.50 \%$ & $0 \%$ & $4 \%$ & $28 \%$ \\
\hline 43 & US CM & India batch & $10.00 \%$ & $0 \%$ & $1 \%$ & $28 \%$ \\
\hline 44 & US CM & India batch & $10.00 \%$ & $0 \%$ & $2 \%$ & $28 \%$ \\
\hline 45 & US CM & India batch & $10.00 \%$ & $0 \%$ & $4 \%$ & $28 \%$ \\
\hline 46 & US CM & India batch & $15.00 \%$ & $0 \%$ & $1 \%$ & $28 \%$ \\
\hline 47 & US CM & India batch & $15.00 \%$ & $0 \%$ & $2 \%$ & $28 \%$ \\
\hline 48 & US CM & India batch & $15.00 \%$ & $0 \%$ & $4 \%$ & $28 \%$ \\
\hline 49 & US batch & India batch & $2.50 \%$ & $0 \%$ & $1 \%$ & $21 \%$ \\
\hline 50 & US batch & India batch & $2.50 \%$ & $0 \%$ & $2 \%$ & $21 \%$ \\
\hline 51 & US batch & India batch & $2.50 \%$ & $0 \%$ & $4 \%$ & $21 \%$ \\
\hline
\end{tabular}


Table 3 (continued)

\begin{tabular}{|c|c|c|c|c|c|c|}
\hline Scenario & Baseline & Comparison & CM cost volatility & Profit margin volatility & Hedge cost & US tax rate \\
\hline 52 & US batch & India batch & $2.50 \%$ & $0 \%$ & $1 \%$ & $28 \%$ \\
\hline 53 & US batch & India batch & $2.50 \%$ & $0 \%$ & $2 \%$ & $28 \%$ \\
\hline 54 & US batch & India batch & $2.50 \%$ & $0 \%$ & $4 \%$ & $28 \%$ \\
\hline 55 & US CM & Ireland batch & $2.50 \%$ & $0 \%$ & $1 \%$ & $21 \%$ \\
\hline 56 & US CM & Ireland batch & $2.50 \%$ & $0 \%$ & $2 \%$ & $21 \%$ \\
\hline 57 & US CM & Ireland batch & $2.50 \%$ & $0 \%$ & $4 \%$ & $21 \%$ \\
\hline 58 & US CM & Ireland batch & $10.00 \%$ & $0 \%$ & $1 \%$ & $21 \%$ \\
\hline 59 & US CM & Ireland batch & $10.00 \%$ & $0 \%$ & $2 \%$ & $21 \%$ \\
\hline 60 & US CM & Ireland batch & $10.00 \%$ & $0 \%$ & $4 \%$ & $21 \%$ \\
\hline 61 & US CM & Ireland batch & $15.00 \%$ & $0 \%$ & $1 \%$ & $21 \%$ \\
\hline 62 & US CM & Ireland batch & $15.00 \%$ & $0 \%$ & $2 \%$ & $21 \%$ \\
\hline 63 & US CM & Ireland batch & $15.00 \%$ & $0 \%$ & $4 \%$ & $21 \%$ \\
\hline 64 & US CM & Ireland batch & $2.50 \%$ & $0 \%$ & $1 \%$ & $28 \%$ \\
\hline 65 & US CM & Ireland batch & $2.50 \%$ & $0 \%$ & $2 \%$ & $28 \%$ \\
\hline 66 & US CM & Ireland batch & $2.50 \%$ & $0 \%$ & $4 \%$ & $28 \%$ \\
\hline 67 & US CM & Ireland batch & $10.00 \%$ & $0 \%$ & $1 \%$ & $28 \%$ \\
\hline 68 & US CM & Ireland batch & $10.00 \%$ & $0 \%$ & $2 \%$ & $28 \%$ \\
\hline 69 & US CM & Ireland batch & $10.00 \%$ & $0 \%$ & $4 \%$ & $28 \%$ \\
\hline 70 & US CM & Ireland batch & $15.00 \%$ & $0 \%$ & $1 \%$ & $28 \%$ \\
\hline 71 & US CM & Ireland batch & $15.00 \%$ & $0 \%$ & $2 \%$ & $28 \%$ \\
\hline 72 & US CM & Ireland batch & $15.00 \%$ & $0 \%$ & $4 \%$ & $28 \%$ \\
\hline 73 & US batch & Ireland batch & $2.50 \%$ & $0 \%$ & $1 \%$ & $21 \%$ \\
\hline 74 & US batch & Ireland batch & $2.50 \%$ & $0 \%$ & $2 \%$ & $21 \%$ \\
\hline 75 & US batch & Ireland batch & $2.50 \%$ & $0 \%$ & $4 \%$ & $21 \%$ \\
\hline 76 & US batch & Ireland batch & $2.50 \%$ & $0 \%$ & $1 \%$ & $28 \%$ \\
\hline 77 & US batch & Ireland batch & $2.50 \%$ & $0 \%$ & $2 \%$ & $28 \%$ \\
\hline 78 & US batch & Ireland batch & $2.50 \%$ & $0 \%$ & $4 \%$ & $28 \%$ \\
\hline
\end{tabular}

percentile for their target VaR and so a less restrictive target such as a $95^{\text {th }}$ percentile net NPV could be used instead, depending on the company's tolerance for investment risk.

For the analysis, a set of hypotheses of interest comparing USA to three non-U.S. sites using CM technology or batch are as follows:

1. For U.S. manufacturing sites, brand company $E\left(\mathrm{NPV}_{C M}\right)-E\left(\mathrm{NPV}_{\text {batch }}\right)>0$

2. For U.S. manufacturing sites, generic company $E\left(\mathrm{NPV}_{C M}\right)-E\left(\mathrm{NPV}_{\text {batch }}\right)<0$

Table 4 Key country assumptions

\begin{tabular}{lll}
\hline Country & $\begin{array}{l}\text { Manufacturing cost index } \\
{[16]}\end{array}$ & $\begin{array}{l}\text { Corporate } \\
\text { marginal tax } \\
\text { rate [17] }\end{array}$ \\
\hline United States & 100 & $21 \%$ \\
China & 96 & $25 \%$ \\
India & 87 & $30 \%$ \\
Ireland & 91 & $12.5 \%$
\end{tabular}

3. For U.S. versus other country sites, brand company $E\left(\mathrm{NPV}_{\text {Batch }}^{\mathrm{US}}\right)-E\left(\mathrm{NPV}_{\text {Batch }}^{\text {non-US }}\right)<0$

4. For U.S. versus other country sites, generic company $E\left(\mathrm{NPV}_{\text {batch }}^{\mathrm{US}}\right)-E\left(\mathrm{NPV}_{\text {Batch }}^{\text {non-US }}\right)<0$

5. For U.S. versus other country sites, brand company $E\left(\mathrm{NPV}_{\mathrm{CM}}^{\mathrm{US}}\right)-E\left(\mathrm{NPV}_{\text {batch }}^{\text {non-US }}\right)>0$

6. For U.S. versus other country sites, generic company $E\left(\mathrm{NPV}_{\mathrm{CM}}^{\mathrm{US}}\right)-E\left(\mathrm{NPV}_{\text {batch }}^{\text {non-US }}\right)<0$

Hypothesis 1 is based on the proposition that the lower cost of CM technology along with higher profit margins with lower variability in those margins will generate positive net NPV for CM over batch technology for brand companies in the USA. However, it is hypothesized that lower $\mathrm{CM}$ costs may not be sufficient to offset the lower profit margins of generic companies and higher cost variability of CM (hypothesis 2). Hypotheses 3 and 4 reflects a view that differential costs and tax rates will make foreign investment in batch technology a preferred investment choice over investment in batch technology in the USA regardless of company type. Finally, hypotheses 5 and 6 reflect a view that lower costs of CM technology in the USA will offset any tax 


\section{Panel A}

Baseline

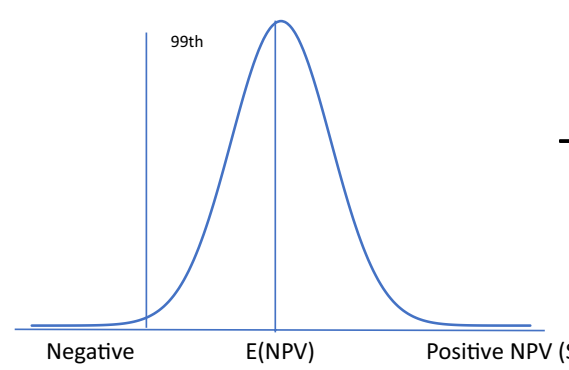

Panel B

Alternative

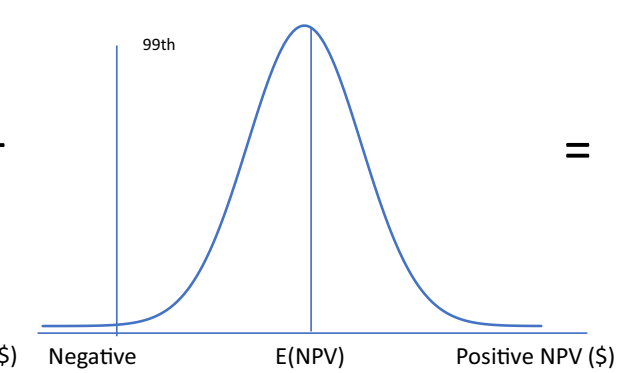

Panel C

Baseline - Alternative NPV

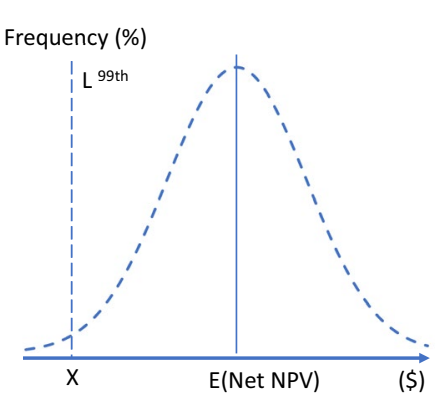

Fig. 1 Investment VaR and net NPV concept. A Baseline. B Alternative. C Baseline-alternative NPV

and cost advantages overseas for brand companies but not for generics, again reflecting differences in profitability and markets for those companies.

\section{Results}

Figure 2 provides a summary of the comparison for brand companies deciding whether to manufacture in the USA leveraging $\mathrm{CM}$ versus batch technology under the $3 \mathrm{CM}$ cost volatility scenarios. The results support hypothesis 1 that for brand companies, NPV for CM-based technology is greater than that using a batch process across all cost volatility scenarios. Moreover, it should be noted that only under the most extreme cost volatility (15\%) scenario and most conservative investment VaR $\left(99^{\text {th }}\right.$ percentile) would batch NPV ever exceed CM NPV. This suggests that at least for U.S. sites, CM manufacturing should be the preferred technology choice for brand companies. These results also hold up when looking across profit margin scenarios for brand companies as shown in Fig. 3. In all scenarios, expected and tail risk net NPVs remain positive, corroborating the cost volatility scenario results above.

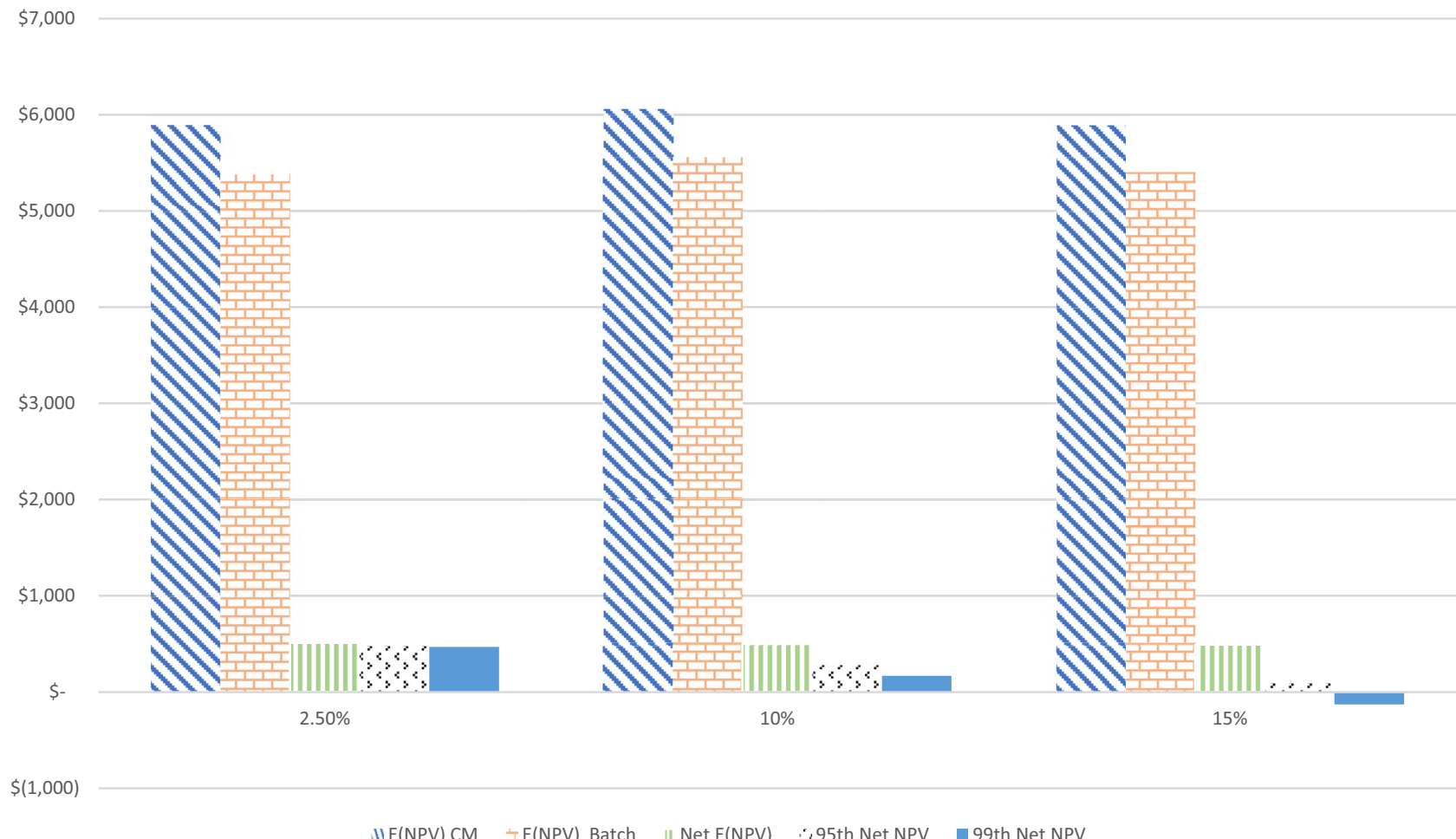

Fig. 2 Brand Company U.S. site technology NPV comparisons by cost volatility scenarios 


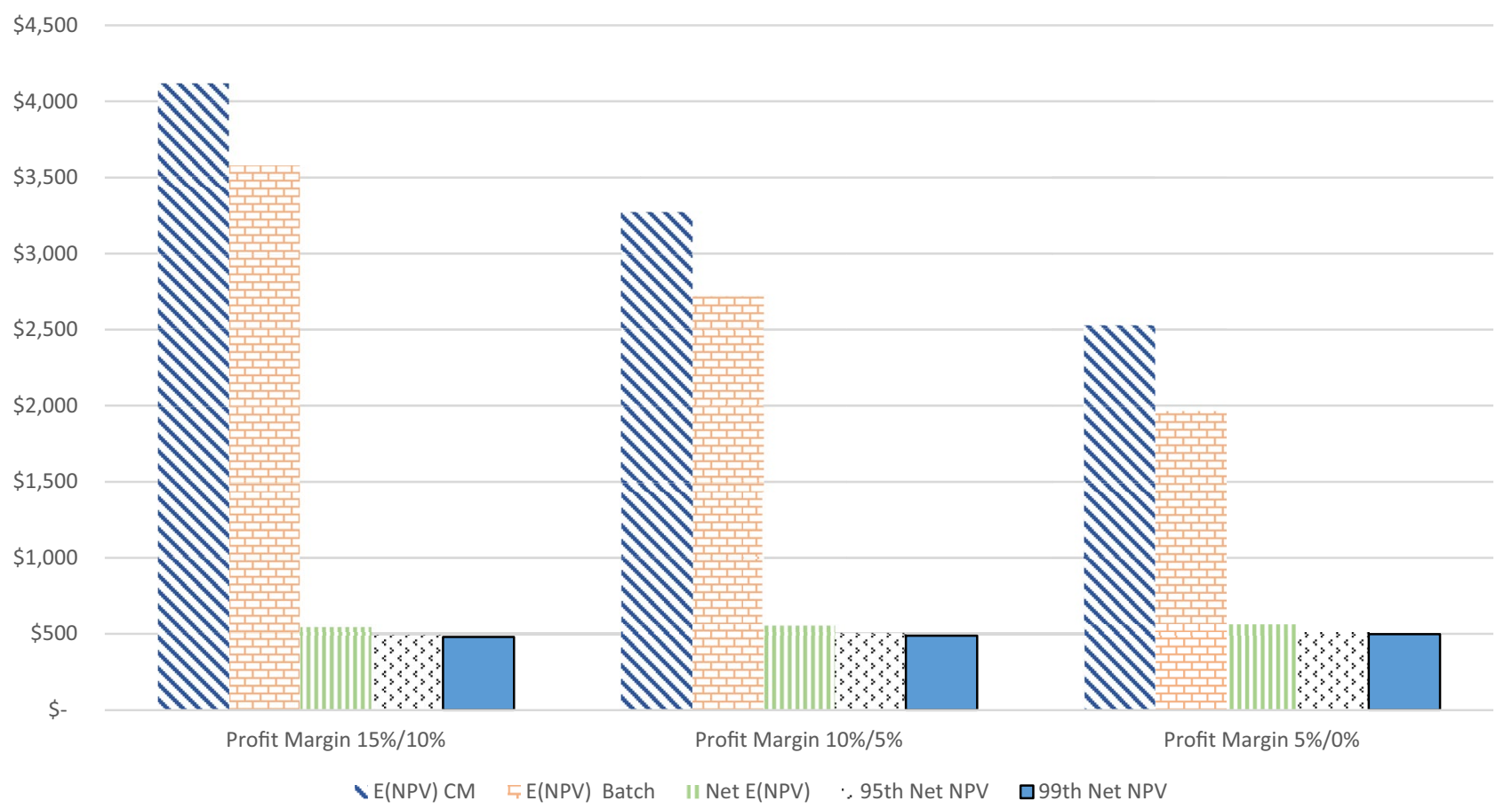

Fig. 3 Brand Company U.S. site technology NPV comparisons by profit margin scenarios

Turning next to generic company manufacturing investment alternatives, hypothesis 2 is not supported by the NPV findings (Fig. 4). For all CM cost volatility scenarios,
CM maintains a positive net $E(\mathrm{NPV})$ over batch processing technology. And with the exception of the $99^{\text {th }}$ percentile outcome under a $15 \% \mathrm{CM}$ cost volatility scenario, CM

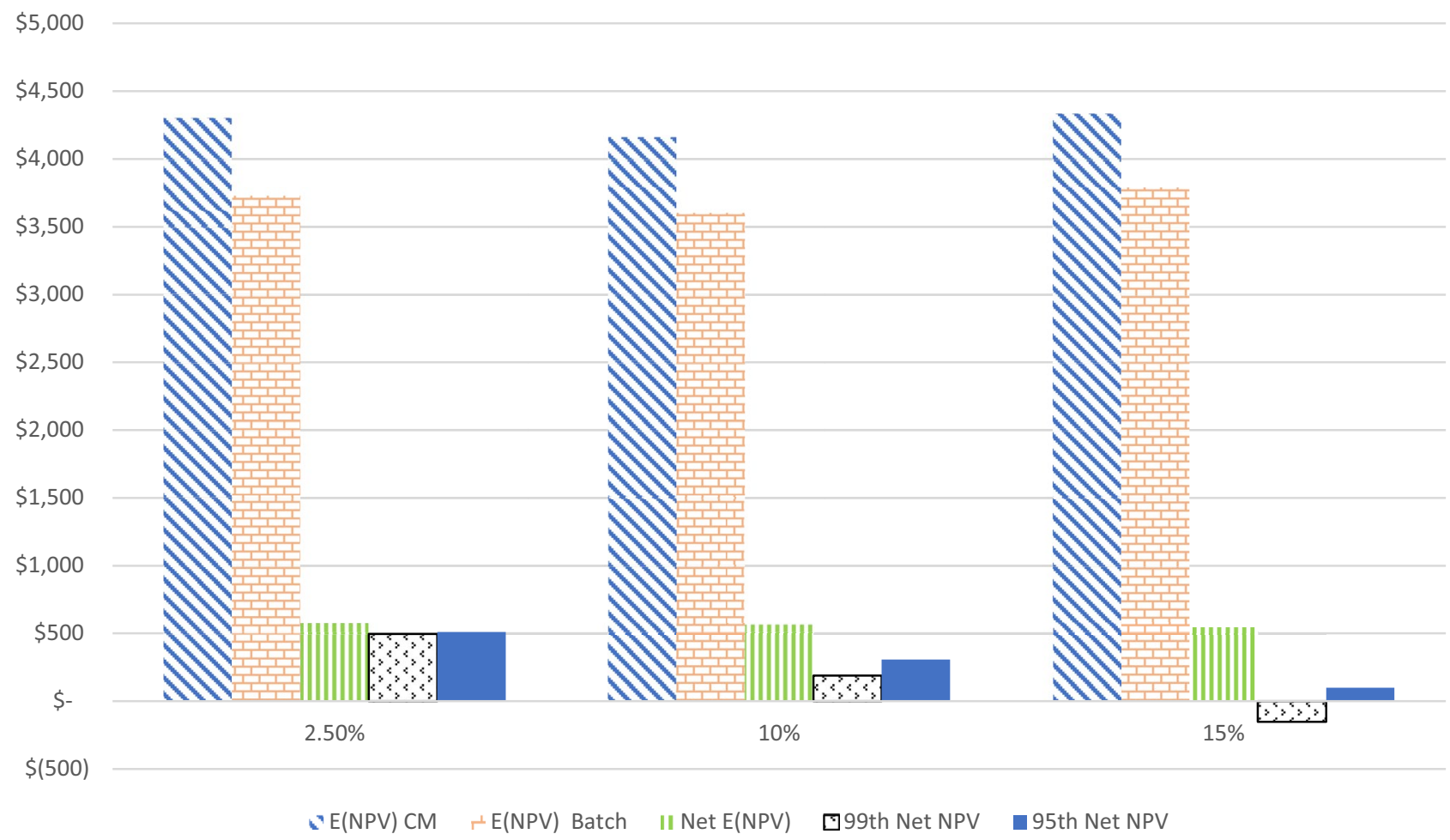

Fig. 4 Generic Company U.S. site technology NPV comparisons by cost volatility scenarios 
dominates batch in the tail of the NPV distribution as well. While generic companies experience a much more competitive environment than brand companies, the cost reduction associated with CM appears to still provide an advantage over more costly batch processes for generic companies. This result is confirmed further in Fig. 5 that shows positive $E(\mathrm{NPV})$ over all profit margin scenarios. And none of the net NPV tail risk scenarios are negative, suggesting that even for generic companies, CM technology would be preferred over batch on an NPV basis.

To investigate U.S. competitiveness with other key countries manufacturing pharmaceutical products, an NPV comparison of investing in batch processes in the USA versus China, India, or Ireland was made. The results from this analysis are found in Figs. 6 and 7 for brand and generic companies, respectively. The baseline tax scenario assumed U.S. marginal corporate tax rates of $21 \%$ under the foreign exchange hedge costs scenarios noted previously for the other countries.
The results indicate that compared to investing in batch technology in China and India, investing in batch technology in the USA would result in net positive $E(\mathrm{NPV})$ across all hedge cost scenarios. For the China and India scenarios, net NPVs at the $95^{\text {th }}$ and $99^{\text {th }}$ percentile are positive as well.

These results suggest that under current U.S. tax policy, investment in U.S. pharmaceutical manufacturing using batch technology would generate higher expected net NPVs than in China or India and also under more extreme NPV outcomes. The fact that investment in batch technology in the USA would generate higher expected NPV over investment in the same technology on China or India suggests that relative costs, tax policy, and market conditions may already favor U.S. pharmaceutical manufacturing investment.

The results, however, are much different when considering Ireland as a manufacturing site. Due to much lower corporate tax rates than the USA (21\%), Ireland (12.5\%) enjoys an advantage that results in negative net $\mathrm{E}(\mathrm{NPV})$ for all hedging cost scenarios. These results underscore the

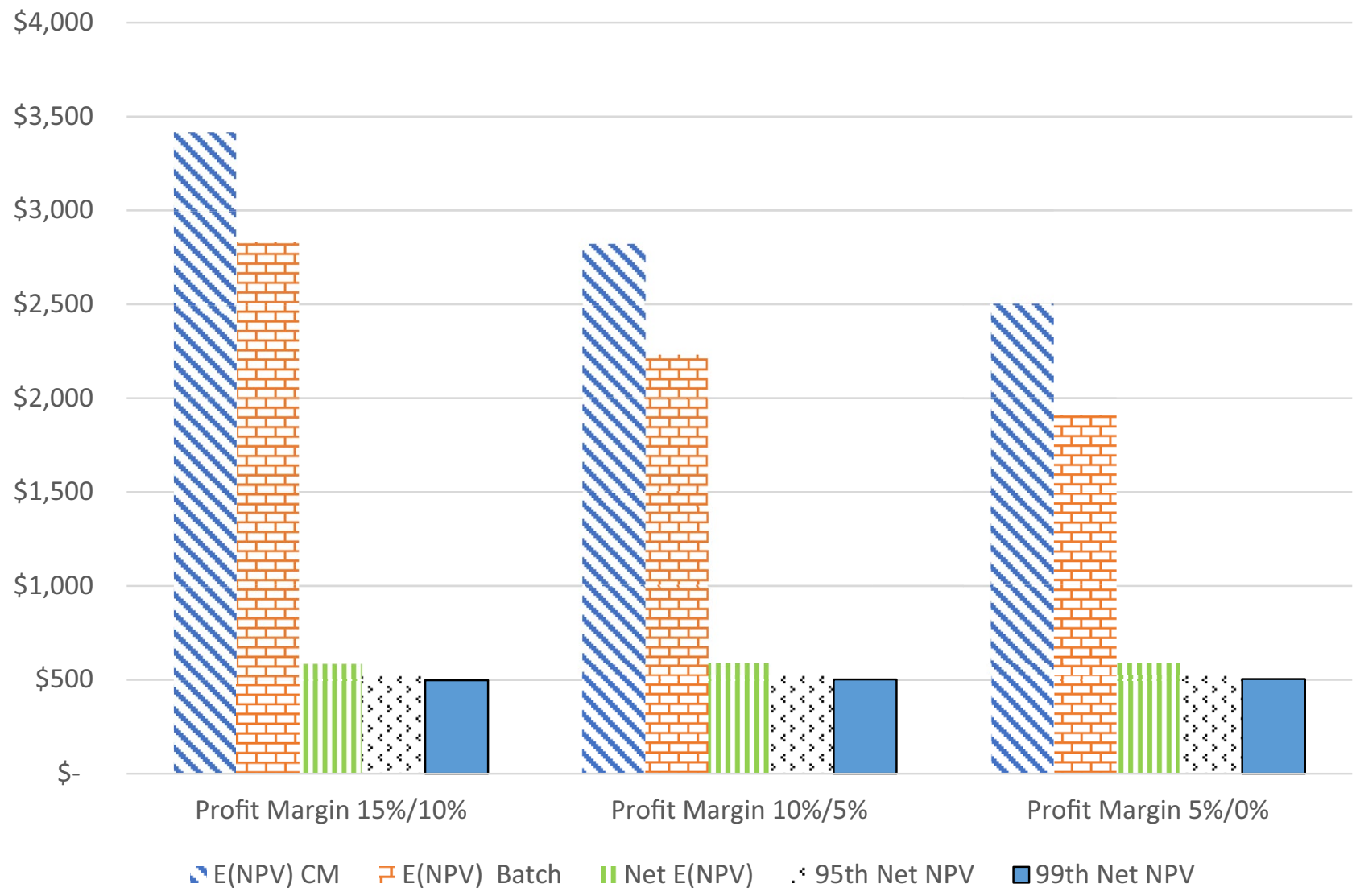

Fig. 5 Generic Company U.S. site technology NPV comparisons by profit margin scenarios 


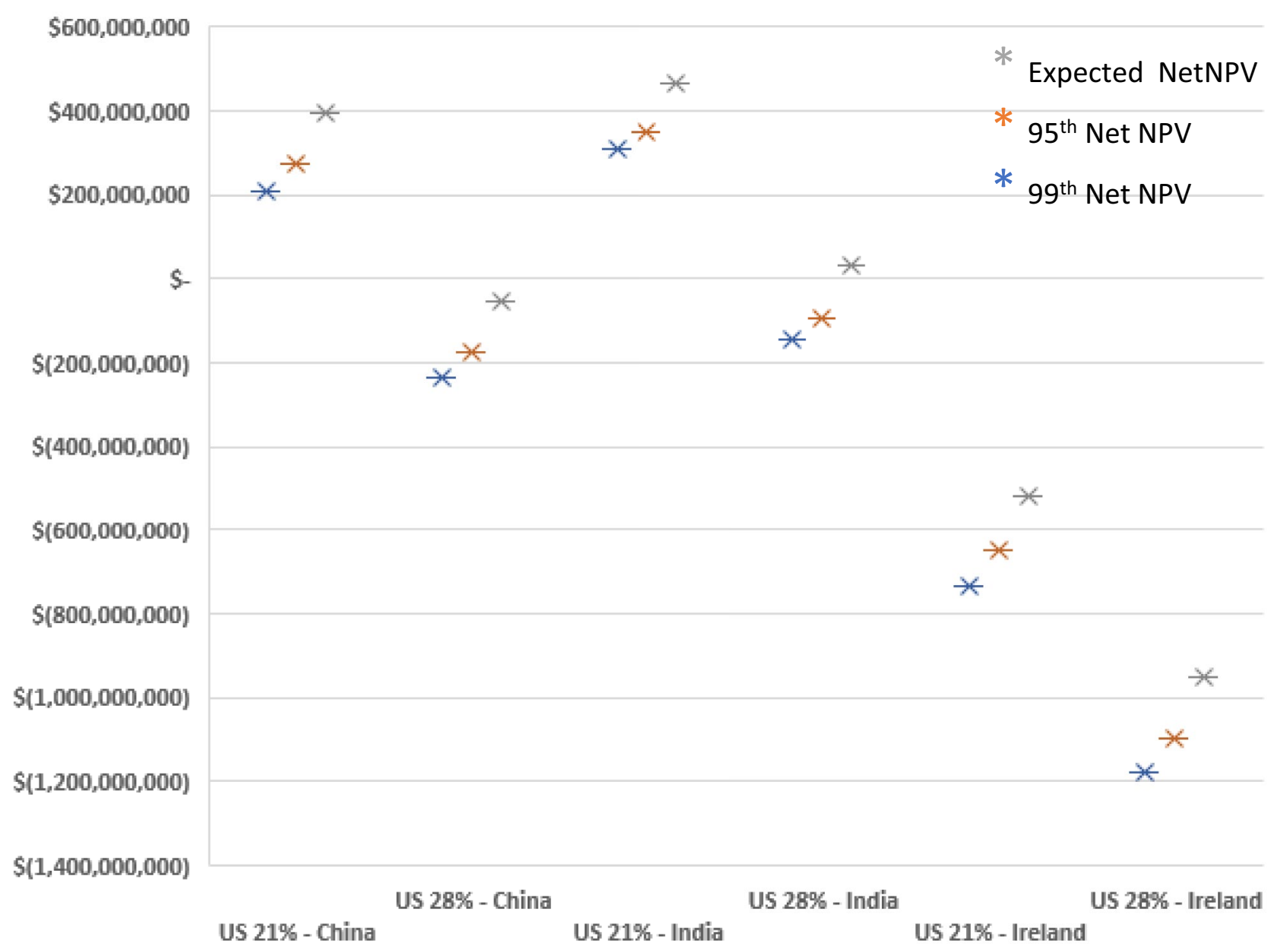

Fig. 6 Brand Company batch investment net $E(\mathrm{NPV})$ in the USA vs. non-US sites

importance of tax policy in manufacturing decisions absent technology as a factor of production.

Another set of scenarios were run assuming an increase in U.S. corporate tax rates to $28 \%$ to better understand how changes in tax policy would affect decisions to invest in domestic pharmaceutical manufacturing facilities. Corporate investment decisions are affected by a host of financial and nonfinancial factors including differential corporate tax rates across the world. Applying a $28 \%$ corporate tax to U.S. pharmaceutical manufacturing investments would lead to negative net NPVs for both brand and generic companies in the USA to China scenarios. And increasing corporate tax rates in the USA to $28 \%$ would drastically reduce net
NPV outcomes compared to investing in India under a $21 \%$ U.S. corporate tax rate scenario. These results have major implications for redirecting pharmaceutical manufacturing to the USA. The results overall comparing USA to non-U.S. investment for batch technology are contrary to hypotheses 3 and 4 under current U.S. tax rates but corroborate these hypotheses under the China batch manufacturing comparison if U.S. tax rates rose to $28 \%$.

To test hypotheses 5 and 6 , a number of scenarios were generated comparing investment in CM technology in the USA to batch technology in China, India, or Ireland assuming a $21 \%$ U.S. corporate tax rate and all CM cost volatility and hedge cost scenarios. The results from those scenarios 


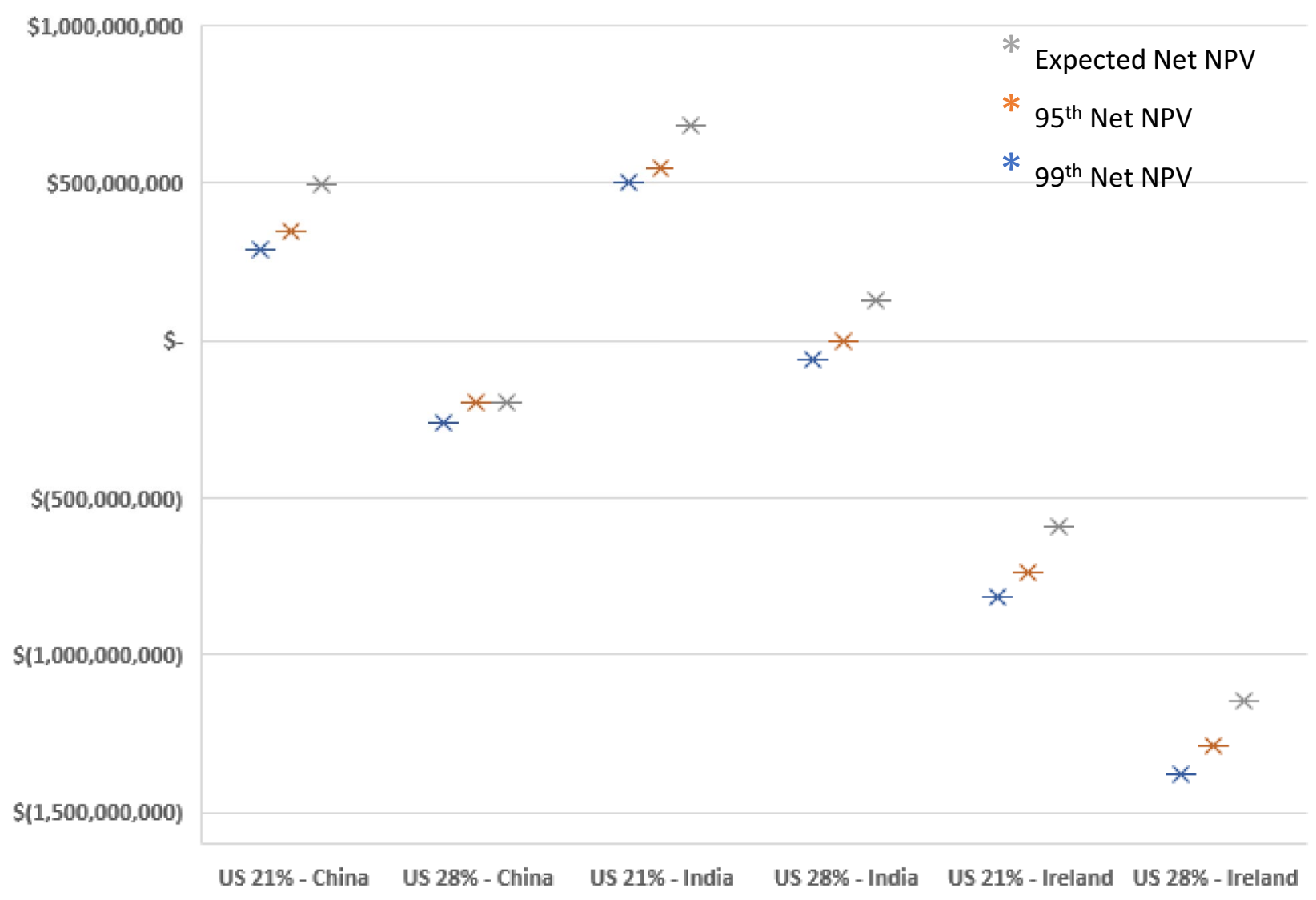

Fig. 7 Generic Company batch investment net E(NPV) in the U.S. vs. non-US sites

are summarized in Figs. 8 and 9. Not surprising given their substantially lower costs than batch, CM technology investment in the U.S. generates a positive net $E(\mathrm{NPV})$ compared against batch technology investment in China or India. All but two (three) of the nine scenarios generate positive net NPVs at the $99^{\text {th }}$ percentile for brand (generic) companies in the China scenarios. Between a third to about half of the India scenarios result in positive net NPVs at the $99^{\text {th }}$ percentile. Even taking into account CM's lower costs, investing in U.S. CM manufacturing still is not as attractive on an expected net NPV basis as investing in batch processing in Ireland. The combination of lower manufacturing costs and tax rates in Ireland appear to be driving these results. Finally, for scenarios applying, a possible 28\% U.S. corporate tax rate, CM manufacturing in the U.S. versus batch processing in China or India is less attractive as expected net NPV declines compared to the $21 \%$ U.S. tax rate scenarios. 


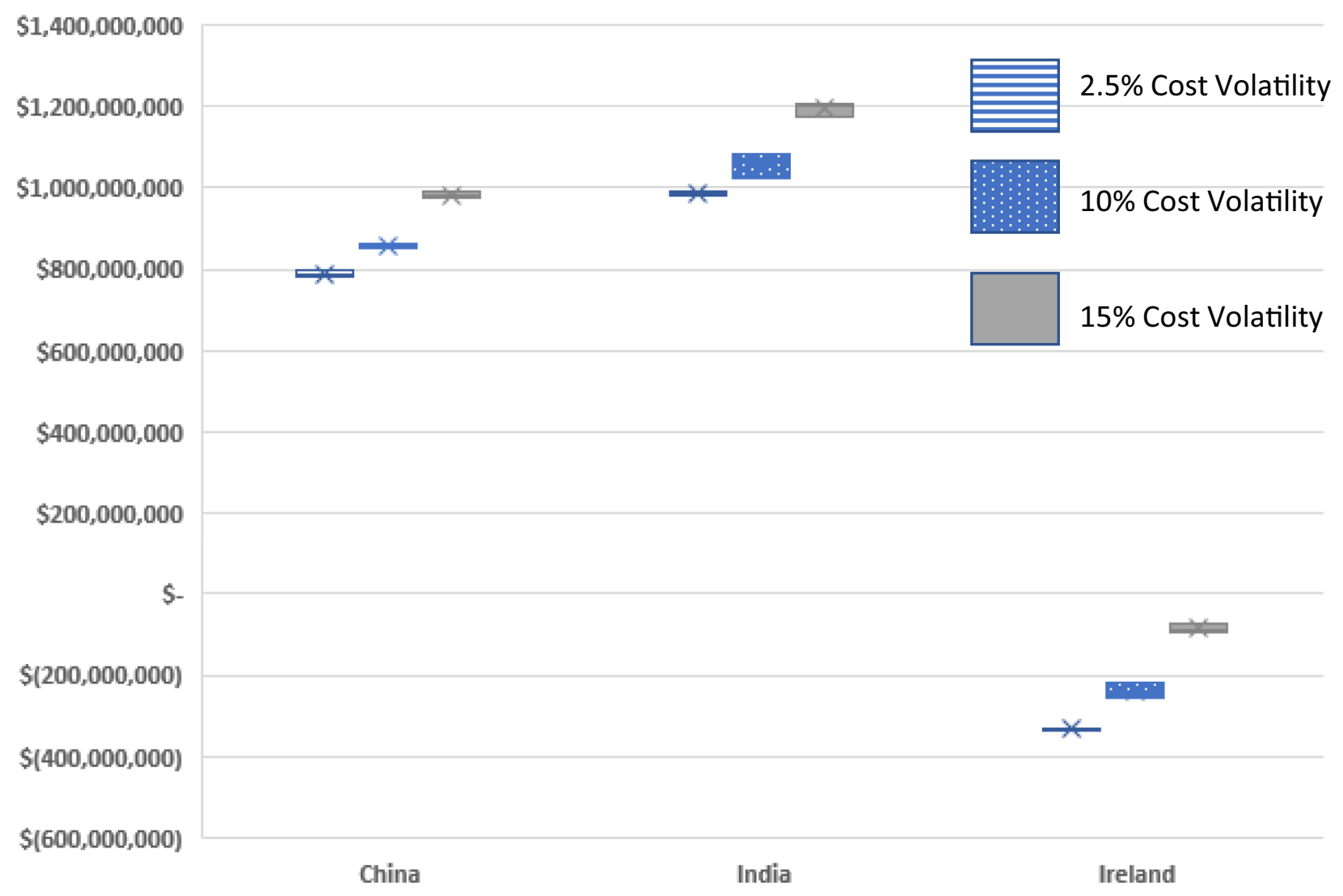

Fig. 8 Brand Company U.S. CM vs. non-US batch investment net $E(\mathrm{NPV})$ 


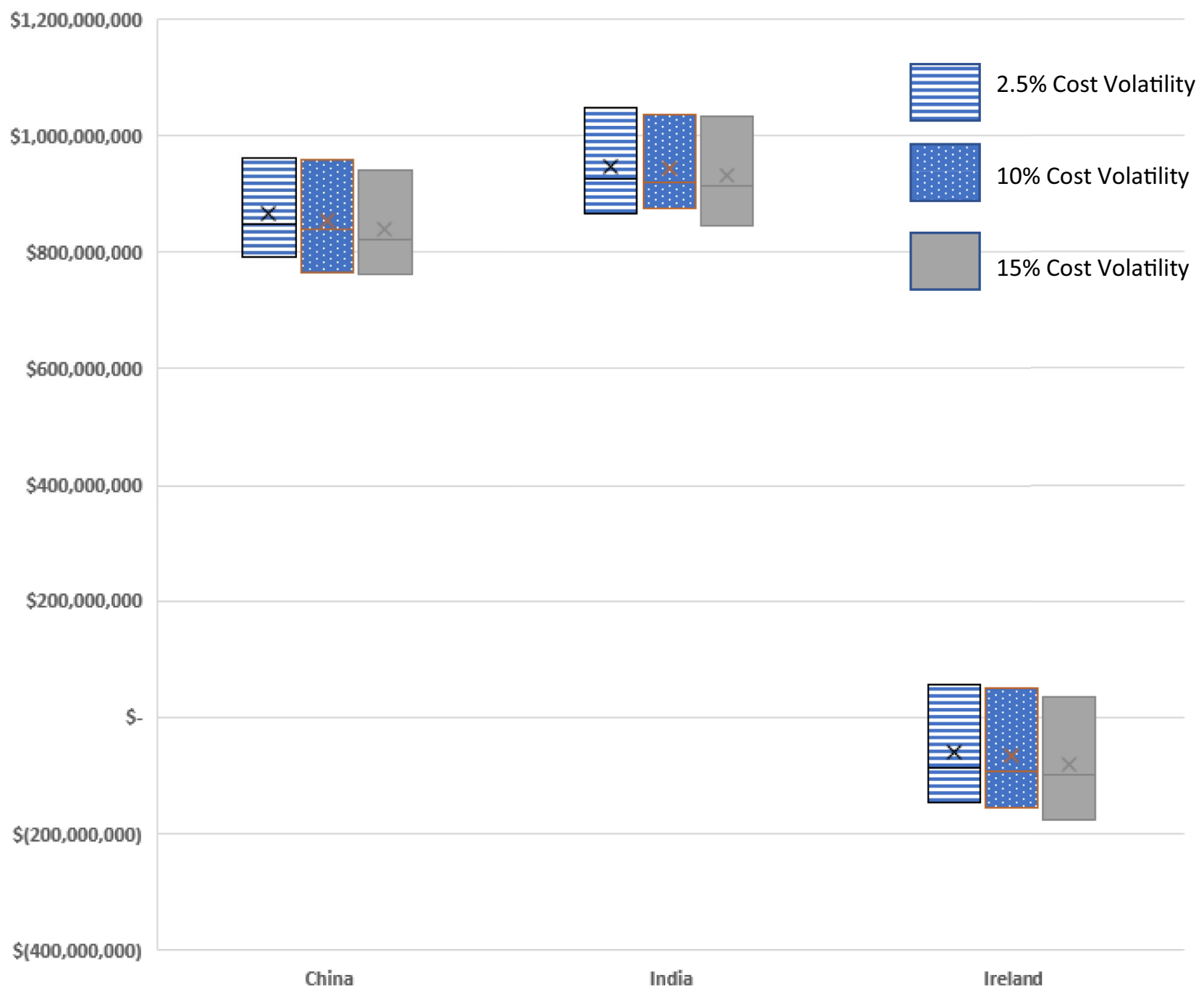

Fig. 9 Generic Company U.S. CM vs. non-US batch investment net $E(\mathrm{NPV})$

\section{Conclusions}

The results of the NPV simulations have important implications for pharmaceutical company investment in CM manufacturing technology over current batch processing as well as for domestic versus foreign investment. The major findings are summarized as follows:

\section{Finding 1}

When looking at comparing investment in either CM or batch for a new U.S. facility, the results clearly suggest that the lower costs associated with CM technology should lead to both brand and generic companies investing in more $\mathrm{CM}$ manufacturing technology. While the result conformed to expectations for brand companies based on their larger and less volatile profit margins, it was somewhat surprising for generic companies, taking into account scenarios where CM cost volatility was increased substantially beyond the baseline batch cost volatility.

\section{Finding 2}

The simulation analysis demonstrated that under current U.S. tax rates, investing in batch technology at U.S. sites would be economically more attractive than investing in batch technology in China or India. Somewhat lower manufacturing costs in these countries appear to be insufficient offsets to foreign exchange hedging costs and lower corporate tax rates in the US. However, much lower tax rates in Ireland make that country extremely competitive relative to the USA such that despite lower CM costs, investing in batch processing in Ireland provides higher NPV to both brand and generic companies across scenarios. 


\section{Finding 3}

Investing in CM technology in the USA under current tax rates results in positive expected net NPVs over batch technology investments in China or India for both brand and generic companies. Lower U.S. corporate tax rates, and CM manufacturing costs along with no hedging costs in the U.S. scenarios drive those results.

\section{Finding 4}

U.S. tax policy has a material impact on whether pharmaceutical companies would decide to invest in the USA or not for their manufacturing. When U.S. corporate tax rates were raised from 21 to $28 \%$, it turned expected net NPVs negative for batch and reduced them for CM technology in the USA versus investing in batch processing in China.

The results demonstrate the potential for $\mathrm{CM}$ to make domestic manufacturing of pharmaceuticals more economically attractive than foreign manufacturing of those products. However, the results do not comport with actual experience. That is, very little investment in CM-based pharmaceutical manufacturing has taken place thus far and most of that investment has been by large brand companies Furthermore, there is no indication that the industry has refocused much of their manufacturing investments toward the USA. This raises serious questions regarding barriers and/or risks that may be preventing these companies from adopting advanced technologies for U.S. pharmaceutical manufacturing.

Factors likely to be driving a lack of investment in CM pharmaceutical manufacturing technology in the USA include the following:

- Lack of solid data on CM investment and operating costs that raises investment uncertainty.

- Potential management bias toward proven technology

- Market factors that favor greater focus on R\&D investment over manufacturing investment

- Regulatory uncertainty regarding product approval leveraging advanced manufacturing processes

- More stringent environmental regulations in the USA

- Differential corporate tax rates between the USA and other countries

- A large percentage of API manufacturing outside the USA. that can affect finished dosage form end products due to supply chain logistics

It will not be sufficient to merely demonstrate financial feasibility of advanced manufacturing technologies given long standing industry structural, economic, and attitudinal issues that have dampened interest in adopting advanced manufacturing technology in the industry thus far. Crafting public policies to address such industry barriers and risks to domestic and advanced technology pharmaceutical manufacturing investment will be essential in ultimately stimulating such investments.

Funding This project is supported by the Food and Drug Administration (FDA) of the U.S. Department of Health and Human Services (HHS) as part of a financial assistance award [U01FD005946] totaling $\$ 285,000$ with $100 \%$ funded by FDA/HHS. The contents are those of the author(s) and do not necessarily represent the official views of, nor an endorsement, by FDA/HHS, or the U.S. government.

\section{References}

1. Hahn SM. US Food and Drug Administration, FDA publishes list of essential medicines, medical countermeasures, critical inputs required by Executive Order, FDA Statement. 2020.

2. US Government Accountability Office. Testimony before the Subcommittee on agriculture, rural development, food and drug administration, and related agencies, committee on appropriations, house of representatives, statement of mary denigan-macauley, director, health care, drug safety FDA's future inspection plans need to address issues presented by COVID-19 Backlog. 2020.

3. FDA. Report to Congress, Drug Shortages for CY 2020. 2021.

4. COVID-19: The CIDRAP Viewpoint October 21, Part 6: Ensuring a Resilient US Prescription Drug Supply. 2020.

5. Center for Drug Evaluation and Research. Office of Pharmaceutical quality, report on the state of pharmaceutical quality: Fiscal Year. 2019.

6. Rose J, Ian C, Michael M, Will K. A manufacturing strategy built for trade instability. BCG. 2020.

7. Asen E. Corporate Tax Rates Around the World, 2020, Tax Foundation, December 9, 2020.

8. FDA, Center for Drug Evaluation and Research Office of Pharmaceutical Quality. Report on the state of pharmaceutical quality, assuring quality medicines are available for the American Public. 2018.

9. Code of Federal Regulations (CFR) Parts 210 and 211. Title 21 - Food and Drug Administration, Department of Health and Human Services, Subchapter C - Drugs: General. Part 210 Current Good Manufacturing Practice in Manufacturing, Processing, Packing, or Holding of Drugs.

10. Schaber SD, Gerogiorgis DI, Ramachandran R, Evans JMB, Barton PI, Trout BL. Economic analysis of integrated continuous and batch pharmaceutical manufacturing: A case study. Ind Eng Chem Res. 2011;50(17):10083-92. https://doi.org/10.1021/ ie2006752.

11. Lakdawalla DN. Economics of the pharmaceutical industry. $\mathbf{J}$ Econo Lit. 2018;56(2):397-449.

12. Manning R, Rich S. Bates White Economic consulting, continuous manufacturing in pharmaceuticals: Econo Policy Iss. 2018.

13. Kesselheim AS, Sinha MS, Avorn J. Determinants of market exclusivity for prescription drugs in the United States. JAMA Int Med, AMA Intern Med. 2017. https://doi.org/10.1001/jamainternmed. 2017.4329. Published online September 11, 2017.

14. NASA Cost Estimating Handbook Version 4.0. Appendix G cost risk and uncertainty methodologies. 2015.

15. Achilleos EC, Calandranis, JC, Petrides DP. Quantifying the impact of uncertain parameters in the batch manufacturing of active pharmaceutical ingredients. Pharm Eng The Official Magazine of ISPE. July/August 2006;26(4).

16. BostonConsulting Group. How shifting costs are altering the math of global manufacturing, December 11, 2018.

17. Tax Foundation. Corporate tax rates around the world. 2020.

Publisher's Note Springer Nature remains neutral with regard to jurisdictional claims in published maps and institutional affiliations. 